\title{
Improving Digital Engineering Tools in Complex Product Development by Means of an Adequate Monitoring of Research Projects
}

\author{
Iris de Fontaines ${ }^{1,2}$, Didier Lefeuve ${ }^{1}$, Guy Prudhomme ${ }^{2}$, and Michel Tollenaere ${ }^{2}$ \\ ${ }^{1}$ Eurocopter France, Aéroport MP 13725 Marignane Cedex France \\ ${ }^{2}$ Laboratoire G-SCOP, Grenoble INP, Université Grenoble 1, CNRS UMR5272 \\ 46 Ave. Félix Viallet 38031 Grenoble \\ \{iris.de-fontaines, didier.lefeuve\} @eurocopter.com, \\ guy.prudhommedg-scop.inpg.fr, michel.tollenaeredinpg.fr
}

\begin{abstract}
Complex products development relies on established and tested processes that embed software applications in collaborative PLM systems. Many efforts are performed by companies to improve their development process by means of research projects. However the transfer of research results into industrial processes implies a high level of risk. The maturity assessment and the proof of usage are two criteria that help decreasing the risky transition. Technology Readiness Level (TRL) methodology and usage scenarios are tools which provide evidence associated to those two criteria. In this paper, a methodology is proposed to guide stakeholders in the development of usage scenario in the frame of TRL methodology. Thanks to the proposed methodology, at the end of the research project, the proof of usage and the maturity of engineering technology products are validated and could support their industrialization.
\end{abstract}

Keywords: technology transfer, PLM process improvement, research steering, maturity, TRL, scenarios, proof of usage, BPMN.

\section{Introduction}

PLM provides enhanced tools and methods to perform design and engineering in industry or service activities. Thus PLM is focused on engineering data management, CAD data handling, engineering document management, different natures of bill of materials; it supports the main engineering processes, like authoring, data creation, engineering changes, assessment and approvals between different departments or companies. It is expected from PLM systems to control access rights to the data as read-only, RW, print, via roles of actors within an organization or in an extended enterprise. In the recent decades, improvements in engineering methods have been mainly brought by means of massive introduction of digital engineering [1]. Thus digital engineering is an important part of R\&D efforts in large-scale companies, with digital mockup, multi physics simulations, optimization, virtual reality and support to PLM processes (changes, extended enterprising, data exchange...). 
Aerospace industry develops very complex products, because of the multiple kinds of technology involved (materials, electronics, control...) and the accurate tools in use to assess and optimize the behavior of an aircraft [2]. R\&D departments from the major aerospace companies are massively involved in the improvements of both the technologies embedded in the products (airplanes, helicopters, launchers, satellites, drones) and also the methods and tools (PLM tools) in use for the development process itself. From a sustainable business perspective, both innovative R\&D results are required, the first ones to deliver best in class products to the customers, while the seconds aim at reducing time to market, developing more customized products and optimizing human design resources production. This paper focuses on that latter kind of research results, namely $R \& D$ propositions for methods and tools improvements that tend to improve PLM tools seen as a support to digital engineering processes.

Managing research and innovation implies managing some kinds off risks. Indeed new technologies produced by research project ought to be developed and deployed inside industrial projects. Therefore, research processes should allow studying and anticipating all related impacts and disturbance that might occur when a new technology is inserted in industrial projects. The technology insertion relies on a multidisciplinary decision that implies discussions, contradictions and arguments. Actors of these multidisciplinary teams are invited to decide on a go/no-go way based on the maturity of the new technologies. But how could a "piece of technology" be defined as mature? How could the research process be steered in order to answer maturity requirements'?

In the field of product technology (aircraft system and components), the maturity is assessed thanks to the technology readiness level (TRL) methodology during R\&T projects. Let's remind that this paper deals with the field of method and tools (M\&T). Using TRL methodology in the field of engineering methods and tools opens the following issues: is this TRL methodology transferable for such kind of products? Methods and Tools have not only to show a high level of efficiency from a scientific and technical point of view, but they also have to be usable by stakeholders. In other words, the proof of usage of such method and tools has to be realized as soon as possible. New resources have to be proposed in order to adapt the TRL methodology to this field and to include and assess the proof of usage in research process. Which resources could been associated to the TRL methodology, and how to better anticipate the proof of usage of new technology product? Finally how to qualify those resources?

The study was realized in Eurocopter Company, the manufacturer of helicopters from EADS Company. An action research methodology was applied in order to propose answers to the research issue. As an actor of the research process but also of the industrial process, the researcher analyzed the as-is situation of the technology transfer. The analysis pointed ways of improvement, solved by the integration of scenario inside the TRL methodology. A scenario methodology was developed, and then evaluated on a case study.

The first part of the article explains the major concepts used as the TRL methodology, the proof of usage and the scenario. The second step presents a new approach for assessing M\&T maturity and proof of usage. The third part validates the approach on a Eurocopter case study. 


\section{Definition and Concepts}

\subsection{Maturity of a Technology Product}

Research projects aim, in one hand, to study new technology products and, on the other hand, to reduce risks and uncertainties associated to their future integration into industrial projects. The Technology Readiness Level (TRL) methodology, developed by the NASA [3], is the tool presently in use for assessing technology product maturity. A TRL is a key milestone where the transition from each TRL requires a review to ensure that specific criteria have been considered, completed and validated. The methodology is built around nine levels of readiness [4], rapidly described in Figure 1. From our experience, TRL 6 is a critical level. Indeed it represents the first level of applied research.

However, the TRL methodology is initially developed for space technical products and our study focuses on engineering technology products (processes, tools and methods dedicated to designers and engineers). Is the NASA TRL methodology and criteria adaptable to engineering technology product? Indeed aircraft and engineering technology products transfer success do not depends on the same criteria. Engineering products need to be adopted by future users. The concept of usage needs to be integrated inside the TRL methodology.

\begin{tabular}{|c|c|c|c|}
\hline \multirow{8}{*}{$\begin{array}{l}\text { Technology } \\
\text { product } \\
\text { maturity } \\
\text { growth }\end{array}$} & $\overline{\text { TRL } 9}$ & \multirow{4}{*}{$\begin{array}{l}\text { Mission proven } \\
\text { Certification } \\
\text { Target op. test } \\
\text { Flight test }\end{array}$} & \multirow{3}{*}{ APPLIED } \\
\hline & TRL 8 & & \\
\hline & TRL 7 & & \\
\hline & TRL 6 & & \\
\hline & TRL 5 & \multirow{2}{*}{$\begin{array}{l}\text { Environment test } \\
\text { Lab test }\end{array}$} & \multirow{2}{*}{ ADVANCED } \\
\hline & TRL 4 & & \\
\hline & TRL 3 & \multirow{3}{*}{\multicolumn{2}{|c|}{ 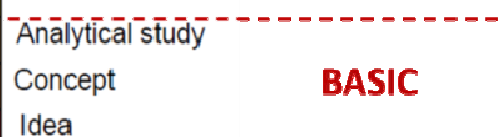 }} \\
\hline & $\overline{T R L} 2$ & & \\
\hline & TRL 1 & & \\
\hline
\end{tabular}

Fig. 1. TRL scale

\subsection{The Proof of Usage}

Engineering technology products are dedicated to designers and are used during aircraft development programs. We distinguish a current way of working, the AS-IS situation where technical and business issues are identified.

The integration and use of new engineering technology products in a new way of working, the TO-BE situation [5], reduce and/or solve those issues.

Users interact with new technology products and the success of user/technology products interactions depends on the success of technology product integration in their functional environment. Therefore requirements and functionalities of technology products have to be co-studied with final users in order to anticipate their 
future usage in TO-BE situation. Furthermore the success of user/technology products interactions depends on users. As [6] points out, a prescribe usage is different of a real one. The success of user/engineering technology product interactions is called the proof of usage. It is validated and verified into a TO-BE situation. The Figure 2 illustrates relationships between technology products and AS-IS/TO-BE situations.

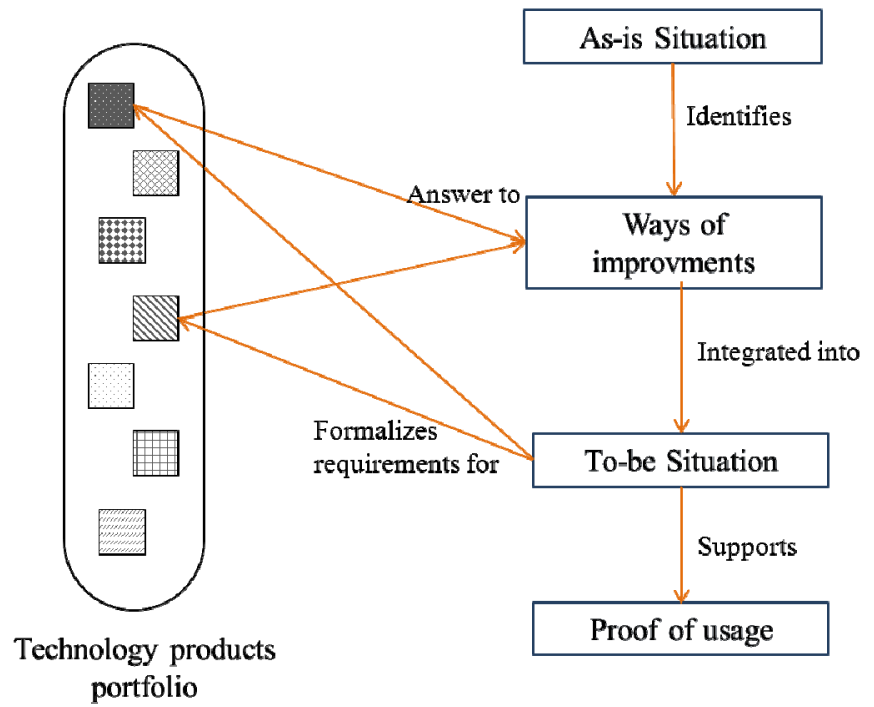

Fig. 2. Relationships between Technology Products, AS-IS/TO-BE situations and Proof of usage

\subsection{Scenarios}

Scenarios are used in different scientific communities as human computer interaction (HCI), software engineering, information systems, requirement engineering and as strategic management community. All those communities have different definitions of scenarios and use them with different goals. [7] and [8] have written two complete papers about scenarios in those different communities. Furthermore, [8] proposes a global and shared definition of a scenario:

"A scenario is a description of the world, in a context and for a purpose, focusing on task interaction. It is intended as a means of communication among stakeholders, and to contain requirements engineering from one or more viewpoints"

The final aim of a scenario is to explore and anticipate a future usage of a product or system [6]. Therefore scenario is a pertinent tool for assessing the proof of usage. Description, context, task are items that define usage scenario. In the context of requirement engineering, [7] proposes a classification framework based on four views: form, content, purpose and lifecycle; themselves qualified by facets and attributes. 
Technology products aim to improve a current situation characterized into an ASIS scenario. The integration of new technology products is realized into a new way of working, the TO-BE scenario.

\section{A New Approach for Assessing Engineering Tools Maturity during Research Projects}

The aim is to assess the maturity of engineering technology products during R\&T projects in order to anticipate development phases.

It has been seen that the TRL methodology contributes to monitor and assess the technology products maturity but seems not sufficient in the case of engineering products. It is proposed to integrate the concept of proof of usage as new criteria of TRL methodology. The proof of usage proves the coherency and validates the user/technology products interactions. Proof of usage is validated thanks to analysis of scenarios.

A new approach is proposed in order to associate proof of usage and scenario with technology readiness levels. The methodology, illustrated in Figure 3, is applied between TRL3 and TRL6. The AS-IS scenario is defined when TRL 3 is assessed and it is not modified all along the process.

\section{- Phase 1: Analysis of usage scenarios}

First Step: Creation and analysis of the AS-IS scenario based on scenario framework [7]: it is a diagnostic step which describes how stakeholders work and collaborate today in order to answer technical and business issues. Based on the AS-IS scenario, ways of improvement are identified

Second Step: Description of TO-BE scenario based on scenario framework: it is a picture of an improved AS-IS scenario which implies the use of new technology products. New technology product answers previous ways of improvement. Users have to plan new processes, new ways of working. In particular, they do not have to be afraid of change [9].

\section{- Phase 2: Technology product requirements and prototypes}

First Step: Based on TO-BE scenario: actors are able to formalize technology product requirements (characteristics, architecture, performance, integration, interfaces).

Second Step: Rapid prototyping of technology products: most of the time technology products are already developed thanks to research project but they have to be adapted to the previous identified requirements.

\section{- Phase 3: Prototypes and requirements validation and TRL assessment}

First Step: Execution of the TO-BE scenario in the TRL associated environment:

At TRL4, critical components are developed and tested with simplified data in a laboratory environment

At TRL5, the whole system is developed and tested with simplified data 
At TRL6, the whole system is tested with real data

Second step: Validation of the adequacy and coherency between the TO-BE scenario developed and the initial requirements. If technology products are not validated, iteration is realized on requirements-prototype steps.

The maturity is assessed thanks to the TRL questionnaire, based on evidence provided by the TO-BE scenario. Associated to the proof of usage, a work has been done on the TRL questionnaire in order to adapt maturity criteria to engineering technology products. For confidentiality restrictions, the questionnaire and proposed criteria could not be shared.

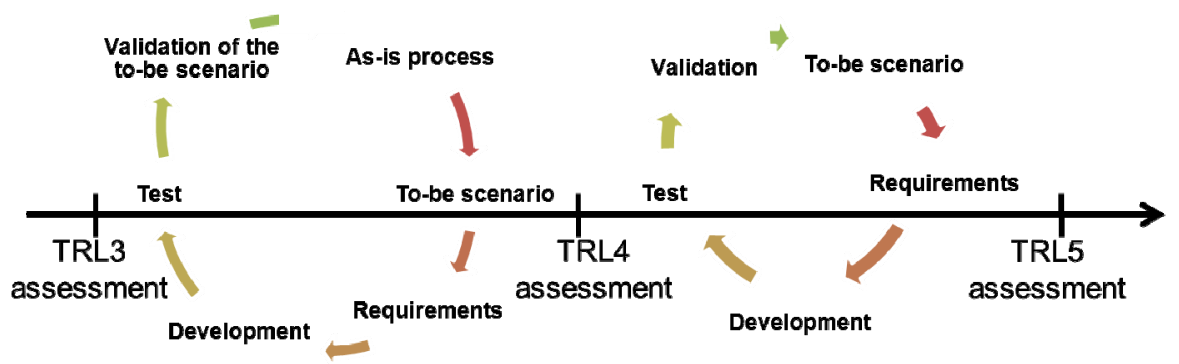

Fig. 3. Description of the two interlocked processes: TRL linear process and cycle usage scenario process

\section{Validation of the New Approach on a Case Study}

An application of the new approach on engineering technology products in Eurocopter Company is described in this part.

\subsection{Construction and Analysis of AS-IS Scenario}

Two issues are treated in the scenario:

- A technical issue consisting in the thermal integration of helicopter engine into its compartment. Ventilations have to be designed on the compartment in order to ensure the cooling of the engine.

- A business issue consisting in ensuring a collaborative work between involved actors. The actors work with non-interoperable tools in different firms.

The two issues were identified by users during interviews and are described in a narrative text. The case was studied in the frame of a European research project named CRESCENDO [10].

The AS-IS scenario describes all activities and data exchanges currently implemented for answering previous issues: the verification and validation of ventilation design of the engine compartment. The scenario was modelled collaboratively between involved actors. A business process model was built by one of the actors, progressively thanks to interviews and reviews with others actors. Because of confidentiality restriction, the 
business model could not been shared. A high-level process, represented in Figure 4, is rather proposed.

Four actors are represented: the engine manufacturer, the CAD designer of the design office, the aerodynamic engineer and the thermal engineer. Ten main information flows leaning on activities, each of them modelled by an arrow, are identified. A narrative text, joined to the process modelling, explains the different steps.

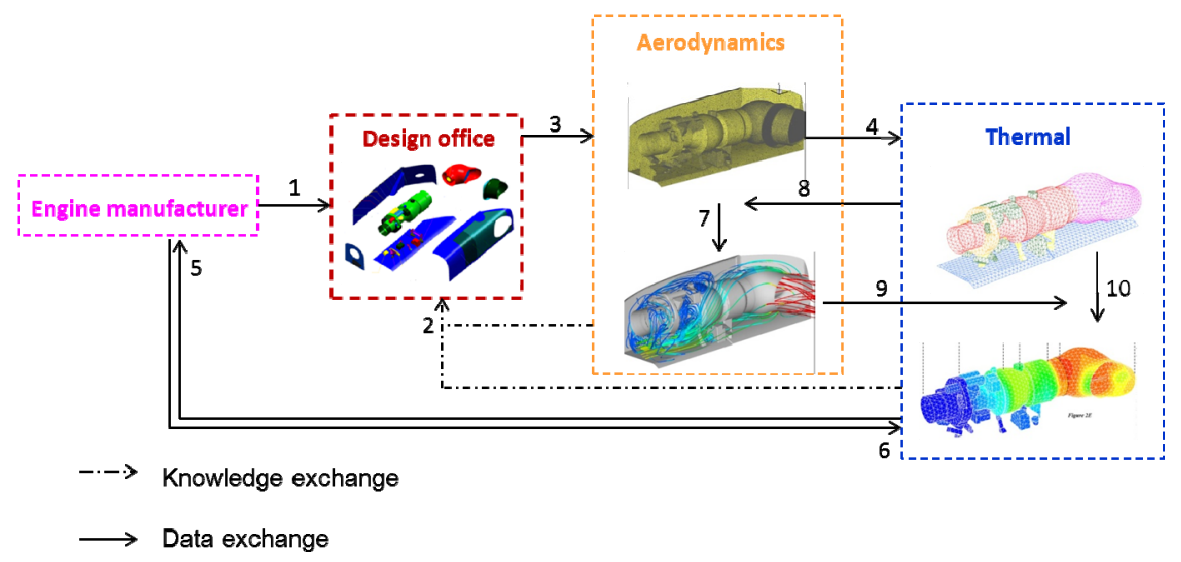

Fig. 4. Business model of the AS-IS scenario

\subsection{TO-BE Scenario: Technology Products Requirements and Prototypes Validation}

Thanks to the AS-IS scenario, ways of improvement are identified:

- new tools for tracing and storing all data and knowledge exchanged

- new working method in order to facilitate the meshing step but also in order to reduce the number of model data set up and calculation

- new modelling and simulation workflow

Those improvements are translated into four technology products, integrated inside a TO-BE scenario, illustrated on Figure 5. Major improvements concern the calculation workflow and data management. It was proposed to realize automated coupling between aerodynamic and thermal disciplines. 


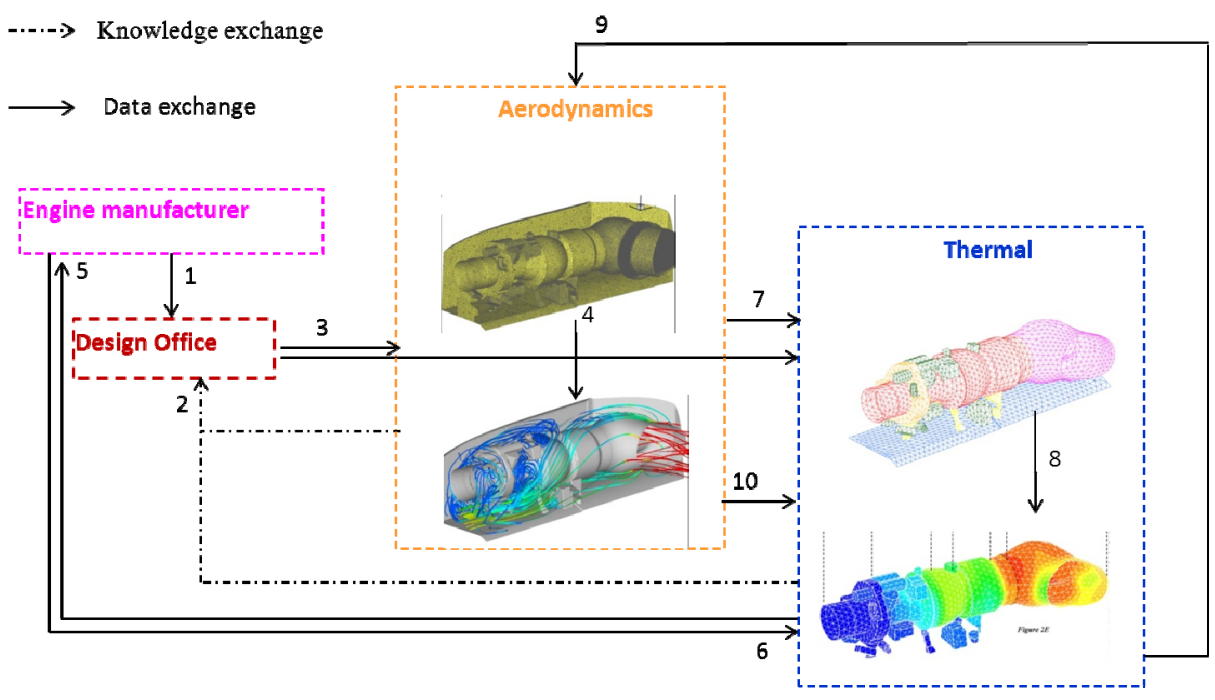

Fig. 5. Business model of the TO-BE scenario

Table 1 summarizes the four technology products.

Table 1. Technology products to develop in the TO-BE process of the usage scenario

\begin{tabular}{lll}
\hline TP & Technology product & Action solved \\
\hline TP1 & $\begin{array}{l}\text { Collaborative calculation work-Iterative automate calculation workflow } \\
\text { flow }\end{array}$ \\
TP2 & $\begin{array}{l}\text { New tools and methods } \\
\text { model set-up and calculation }\end{array}$ & $\begin{array}{l}\text { forA benchmark is realized in order to find the best } \\
\text { tool for each thermal and aerodynamic discipline } \\
\text { with the best interoperability }\end{array}$ \\
TP3 & Surrogate model of the engine & $\begin{array}{l}\text { Improvement and better precision of the engine } \\
\text { behavior } \\
\text { TP4 }\end{array}$ \\
Data management & $\begin{array}{l}\text { Dnowledge, parameters and data exchange all } \\
\text { along the TO-BE process. }\end{array}$ \\
\hline
\end{tabular}

The TO-BE scenario illustrates all the interactions between the technology products themselves and with the firm ecosystem. The analysis of this TO-BE scenario contributes to the formalization of technology product requirements and to their development. Then developed technology products that means prototypes, are tested in the TO-BE scenario. Thanks to the execution, two aspects are verified and validated:

- the global result of TO-BE scenario and so the TO-BE scenario

- the technology products characteristics and ability to answer to user's expectations 


\subsection{Maturity Assessment in a Perspective of Technology Transfer}

Final step is to assess the maturity of technology products. A TRL review is organised and all criteria are discussed. The TRL targeted implies conditions of execution of the TO-BE scenario, which means on previous step.

For a TRL4, TO-BE scenario is executed with simplified conditions (light CADs, local environment, few users). The success of TO-BE scenario validates the proof of usage.

Furthermore, the TO-BE scenario illustrates technology product requirements, environment and interactions. Thus, the scenario is an appropriate tool that allows assessing the technical maturity and the proof of usage of engineering technology product.

\section{Conclusion and Perspectives}

This paper focuses on the monitoring of research results, namely R\&D propositions for methods and tools improvements that tend to improve PLM tools seen as a support to digital engineering processes. The TRL methodology is used during research project for assessing technology product maturity. Proposition is done to improve this methodology in the case of engineering technology product. A new criterion is defined: the proof of usage. It translates the success of the interaction between users and technology. Associated to the proof of usage, scenarios are developed. Two typologies are defined: AS-IS and TO-BE scenarios. Scenario supports the proof of usage assessment. Scenarios are co-developed with impacted stakeholders and are modeled under Business Process Model Notation (BPMN). Thanks to models, TRL criteria are assessed and justified: technology requirements, interfaces, performance, and applications. Furthermore stakeholders can forecast usage related technology products.

However, several TO-BE scenarios could be proposed. Additional works have to be realized on this issue. How could we choose between several TO-BE scenarios? How to evaluate them?

A global approach is proposed in order to monitor research project advancement from TRL3 to TRL6. The validation of TRL6 is the key for technology transfer in development phase. Current approach covers "technologic and business aspects" thanks to the maturity and proof of usage but what about "financial aspects"? Does the proof of usage justify the investment? In practice the multidisciplinary decision at the transition is also based on a business case. Technology products have to prove their added-value. The concept of proof of value [11] has to be defined and integrated in the methodology proposed in part 2.

\section{References}

[1] Terzi, S., Bouras, A., Dutta, D., Garetti, M., Kiritsis, D.: Product lifecycle management from its history to its new role. Int. J. of Product Lifecycle Management 4(4), 360-389 (2010) 
[2] Etienne, A., Guyot, E., Van Wijk, D.V., Roucoules, L.: Specifications and development of interoperability solution dedicated to multiple expertise collaboration in a design framework. Int. J. of Product Lifecycle Management 5(2/3/4), 272-294 (2011)

[3] Department of Defense, Technology Readiness Assessment (TRA) Guidance (2011)

[4] Mankins, J.C.: Technology readiness level, pp. 4-8 (1995)

[5] Cornu, C.: Vers un guide méthodologique pour la définition, la prise en compte des exigences et de contraintes d'interopérabilité et le déploiement de processus d'ingénierie système dans une entreprise multi-sites, Ecole Nationale Supérieure des Mines de Paris (2012)

[6] Pascal, A., Rouby, E.: Construire des scénarios d'aide à la conception de solutions TIC: une approche cognitivo-structurationniste. Le cas KMP. In: SdC 2006 (2006)

[7] Rolland, C., Ben Achour, C., Cauvet, C., Ralyté, J., Sutcliffe, A., Maiden, N., Jarke, M., Haumer, P., Pohl, K., Dubois, E., Heymans, P.: A proposal for a scenario classification framework. Requirements Engineering 3(1), 23-47 (1998)

[8] Jarke, M., Carroll, J.M.: Scenario Management: An Interdisciplinary Approach. Requirements Engineering, 1-31 (1999)

[9] Bergsjo, D., Catic, A., Malmqvist, J.: Implementing a service-oriented PLM architecture focusing on support for engineering change management. Int. J. of Product Lifecycle Management 3(4), 335-355 (2008)

[10] CRESCENDO, CRESCENDO EU Project

[11] Yannou, B.: Which research in design creativity and innovation? Let us not forget the reality of companies. Journal of Design Creativity and Innovation (2012) 